\title{
Creer en los vínculos. Pluralismo religioso y capital social
}

\author{
Saioa Bilbao Urkidi \\ Universidad del País Vasco/Euskal Herriko Unibertsitatea \\ saioa.bilbao@ehu.eus
}

Resumen: En el presente artículo mostramos algunas de las conclusiones obtenidas en la tesis doctoral ${ }^{1}$ elaborada en torno al capital social de tres minorías religiosas (la religión ortodoxa, la evangélica y el islam) en una sociedad que vivió un intenso proceso de secularización, el País Vasco. Para ello, se ha hecho uso de la metodología cualitativa, $y$ a través de las entrevistas realizadas y el método Delphi aplicado, hemos podido conocer cuáles son los vínculos de las comunidades de estas tres confesiones $y$ de qué manera estos vínculos, o la ausencia de los mismos, ayudan o dificultan su desarrollo en la sociedad vasca.

Palabras clave: pluralismo religioso, minorías religiosas, capital social.

\section{Believing in the connections. Religious pluralism and social capital}

Abstract: In the present article we show some of the conclusions from a doctoral dissertation on the social capital of three religious minorities (Orthodox Christians, Protestants and Muslims) in the Basque Country, a society that underwent an intense process of secularization. To do so we have used a qualitative methodology and the applied Delphi method during the interviews that we have conducted. As a result, we have been able to describe the bonds within the communities of these three faiths and how these links, or the absence of them, help or hinder their development in Basque society.

Keywords: religious pluralism, religious minorities, social capital.

1 El presente artículo forma parte de la tesis doctoral titulada: El capital social de las minorias religiosas en el País Vasco, y defendida en la UPV/EHU en julio de 2015. 


\section{Introducción}

Uno de los elementos que caracteriza a las actuales sociedades posmodernas es la diversidad y el pluralismo. Más concretamente, la diversidad religiosa es quizá uno de los aspectos más visibles para una sociedad que, como la que analizamos en el presente artículo, ha sufrido un acelerado proceso de secularización. Esta paradoja tiene mucho que ver con el nuevo lugar social que adopta la religión en nuestra sociedad más cercana, la vasca. Hasta fechas muy recientes la sociedad vasca podría caracterizarse como una sociedad con hegemonía y dominación manifiestamente católica.

Esta diversidad religiosa en el País Vasco se ha visto acentuada a partir de un momento clave que confluye con un proceso de globalización en el que el fenómeno migratorio es uno de sus mayores exponentes. Es cierto que diferentes religiones llevan conviviendo, o mejor dicho, coexistiendo, desde hace décadas, pero parece innegable que la llegada de personas de otros países ha intensificado $y$, en cierta medida, desvelado y reafirmado esta diversidad ya existente, tanto de manera cuantitativa (incrementando el número de personas creyentes de las confesiones ya existentes) como de manera cualitativa (creando comunidades pertenecientes a religiones que hasta ese momento no tenían presencia en el territorio vasco).

Parecería, pues, que estamos ante un hecho que asume sentidos contrarios: por un lado, la sociedad autóctona, por decirlo de alguna manera, se aleja de la religión y la abandona, al menos en su versión de creencia, sin que por ello necesariamente decline el ritualismo; por otro, emergen confesiones que estando instaladas tiempo ha en la sociedad vasca se han visto fortalecidas con la incorporación de nuevos miembros llegados a través de los procesos inmigratorios, procesos que también han permitido que se instalen ex novo otras confesiones.

En el presente artículo queremos mostrar, a grandes rasgos, la fortaleza o ausencia de la misma, del asentamiento de algunas de estas confesiones religiosas, con base en el capital social de sus comunidades.

\section{El capital social}

En el presente artículo nos vamos a centrar en tres de las confesiones religiosas minoritarias que tienen presencia en el País Vasco, más concretamente: la cristiana ortodoxa, la evangélica y el islam. Estas fueron las confesiones seleccionadas para el trabajo de tesis doctoral, ya que, por recorrido y características, podía abarcar una variedad de realidades sobre las distintas confesiones. En el momento de realización de la tesis, en el País Vasco, había presencia de un total de diez 
confesiones religiosas además de la católica; además de las tres nombradas, la fe báhái, el budismo, la Iglesia de los Testigos Cristianos de Jehová, la Iglesia de la Cienciología, la Iglesia de Jesucristo de los Santos de los Últimos Días, Lectorium Rosacrucianum y la Iglesia cristiana adventista del Séptimo Día.

El objetivo es conocer la realidad de estas tres confesiones y sus comunidades en el País Vasco a través del análisis de su capital social, entendiendo este como «un importante recurso que poseen los individuos y las sociedades en la medida en que interactúan, y que les permite la consecución de metas o el acceso a determinados recursos, que en ausencia de esta "infraestructura" hubiera sido más difícil o imposible conseguir» (Gallo y Garrido, 2009: 7).

Han sido muchos los autores que se han adentrado desde las ciencias sociales en este término y han ido elaborando definiciones y teorías varias. Entre estos encontramos a autores como Bourdieu, que entiende el capital social como «[... ] la suma de recursos reales o potenciales que se vinculan con la posesión de una red duradera de relaciones de conocimiento y reconocimiento mutuo - afiliación a un grupo- más o menos institucionalizadas que le brinda a cada uno de los miembros del respaldo del capital socialmente adquirido [... ]» (Bourdieu, 1986: 248).

Por su parte, Robert Putnam entiende el capital social como una reserva comunitaria, lo define así: «El capital social se refiere a las características de organización social, tales como la confianza, las normas y redes, que pueden mejorar la eficiencia de la sociedad al facilitar la acción colectiva» (Putnam, 1993a: 167). Este autor distingue dos tipos de capital social: por un lado, el de vínculo (bonding social capital), cuando sirve para reforzar la identidad propia y la homogeneidad interna; por otro, el capital social puente (bridging social capital), que hace referencia a las relaciones más allá del propio grupo y de carácter más heterogéneo, resultando ser más inclusivo.

Por lo tanto, el primer tipo de capital social que hemos analizado es el capital social de vinculo (bonding social capital), entendido como «[...] las conexiones entre personas que comparten algunas características demográficas como la familia o parentesco. Se trata de la cooperación que se deriva de la relación dentro de un grupo homogéneo» (Woolcock y Sweetser, 2002).

Según Bourdieu (1986), practicar y poseer este tipo de capital y dar lugar a este tipo de capital social en forma de confianza, autoridad y normas propias se convierte en una inversión y recurso en reconocimiento mutuo, reproducción y preservación de la posición dominante como grupo, así como de sus valores expresivos e identitarios. En nuestra investigación, nos referiremos a las relaciones que se generan ad intra de las comunidades religiosas, porque estamos hablando de la vinculación que une el individuo al grupo, o viceversa. 
El capital social de puente, por su parte, logra conectar a los individuos de un grupo con otros grupos, generando sinergias y redes de relaciones que traen posibilidades de acceso a diferentes recursos, como la información, las redes, el conocimiento, etc., de procesos. «El capital social puente se refiere a las conexiones entre personas que no son como tú en algunos aspectos demográficos» (Woolcock y Sweetser, 2002: 26).

Con este capital queremos referirnos a las relaciones o conexiones que se generan entre diferentes comunidades religiosas o entre comunidades religiosas y otras entidades — tercer sector, asociaciones u otro tipo de entidades- En este sentido, el capital de vinculación es la base para garantizar la textura del capital social en el grupo de que se trate y sobre su desarrollo es posible construir el de puente.

Fue Woolcock (1998) quien sumó un tercer tipo de capital social, el capital social de acceso, cuando esas relaciones son de un determinado tipo, y permiten que el grupo o comunidad pueda acceder a la estructura institucional y de poder de la sociedad, sea cual sea la forma que adopte el poder en la sociedad de que se trate. Así, «el capital social de acceso pertenece a las conexiones con las personas que tienen poder, estén en posiciones de influencia política o económica» (Woolcock y Sweetser, 2002:26). Más concretamente, como señala el propulsor de este tercer tipo de capital social, «el capital social de acceso también incluye conexiones verticales con las instituciones formales» (Woolcock, 2001).

Este tipo de capital hace referencia a las relaciones que se establecen entre o con los individuos o grupos con agentes que se encuentran en posiciones de poder más influyentes, como pueden ser los poderes públicos. Se trata de un acceso a instancias de poder, que, de otra manera, sería difícilmente alcanzable.

\section{Metodología}

Para analizar el capital social de las comunidades religiosas pertenecientes a las tres confesiones seleccionadas, hemos hecho uso de la metodología y técnicas cualitativas. Nos hemos decantado por la técnica de las entrevistas semiestructuradas y hemos elaborado un guion para orientar las mismas, aunque, como su nombre indica, hemos dejado margen para posibles comentarios o informaciones que se escapen a este. Estas entrevistas se las hemos hecho tanto a representantes de las comunidades religiosas como a miembros de las mismas. En total se han realizado 53 entrevistas. Además, se ha utilizado la técnica Delphi con miembros de las comunidades, así como con personas expertas en la materia.

Para obtener la información y el directorio de las confesiones minoritarias en el País Vasco se ha partido de la base de la información disponible en el Registro 
de Confesiones Religiosas del Ministerio de Justicia, así como de otros estudios de carácter local. Una vez iniciadas las entrevistas se ha aplicado la técnica de bola de nieve para obtener información adicional de otras comunidades religiosas. Esta técnica nos ha permitido acceder, además de a líderes conocidos, a verdaderos y desconocidos hasta entonces «prescriptores de opinión», personas que ocupan una posición estratégica de influencia, aunque no estén situadas en lugares públicos o en primer plano.

Una vez obtenida la información, hemos creado unas dimensiones referentes a cada uno de los tipos de capital social para poder realizar el análisis respectivo.

\section{Principales resultados}

A continuación, vamos a realizar un resumen de conclusiones del capital social analizado de las diferentes comunidades religiosas, pertenecientes a las tres confesiones analizadas.

\subsection{La fortaleza, una cuestión primordial}

La fortaleza de las comunidades religiosas, por la importancia que los elementos que la componen constituyen, resulta de crucial importancia para la consecución de los objetivos tanto intrínsecos como derivados de su actividad. Con la mención a los objetivos intrínsecos nos referimos al hecho de profesar la fe a través del culto, las oraciones o la celebración de festividades propias de cada confesión. Por otro lado, son muchas las iniciativas y actividades que emprenden: clases de formación, iniciativas de asistencia e intervención social, prestación de servicios... Para todo ello, son diversos los indicadores que nos muestran cuál es el grado de fortaleza de estas comunidades, como el recorrido temporal del colectivo, el volumen y vitalidad de la comunidad, la disponibilidad de un espacio y su adecuación, así como la financiación de la que disponen.

La veteranía de las comunidades o su trayectoria temporal implican una diferencia en la fortaleza de las comunidades. Se observa una diferencia tanto entre confesiones como entre comunidades de una misma confesión. Muchas de estas comunidades se han creado por la llegada de personas de diversos orígenes, es decir, por la llegada de la población inmigrante extranjera.

Eso es así al menos de una forma más palpable en el caso de las Iglesias ortodoxas y en las comunidades musulmanas, y en menor medida en el de las comunidades evangélicas, que tienen un recorrido más largo y que ya algunas, compuestas por personas autóctonas, tienen una veteranía consolidada. Los flujos migratorios comenzaron de manera significativa en el territorio vasco a partir 
del año 2000, con lo que muchas comunidades aún tienen un recorrido temporal corto, no llegando ni a la quincena de años. Por el contrario, algunas comunidades evangélicas se remontan incluso al siglo xIX, aunque la mayoría data de la década de los ochenta del siglo pasado.

Teniendo en cuenta que las personas fieles de la religión ortodoxa son en su mayoría de origen de los países de Europa del Este, en la siguiente tabla podemos observar el incremento de la llegada al País Vasco de personas sobre todo de origen rumano. Mientras que en el año 2004 eran 2.652 las personas empadronadas en los municipios vascos, en el año 2003 el número de personas de origen rumano se ve incrementado a 17.350. En menor medida, pero también se ha ido incrementando el número de personas empadronadas de origen ruso, georgiano y serbio.

Tabla 1. Evolución de la población de Europa del Este en el País Vasco

\begin{tabular}{|l|r|r|r|r|}
\hline País & 2004 & $\mathbf{2 0 0 8}$ & $\mathbf{2 0 1 0}$ & 2013 \\
\hline Rumanía & 2.652 & 12.843 & 15.217 & 17.350 \\
\hline Rusia & 434 & 606 & 696 & 796 \\
\hline Georgia & 139 & 457 & 576 & 673 \\
\hline Serbia & 0 & 100 & 90 & 90 \\
\hline
\end{tabular}

En el caso de las personas con base en su origen, que en gran medida profesan el islam, en la siguiente tabla observamos cómo el número de personas empadronadas de origen marroquí se ha incrementado de 1.370 personas en el año 1996 a 17.832 en 2012. Las personas de origen argelino, por su parte, han pasado de ser 108 a 5.965, y, aunque en menor medida, también se ha incrementado el número de personas de origen senegalés y pakistaní.

Tabla 2. Evolución de la inmigración por nacionalidades representativas en el Islam

\begin{tabular}{|l|r|r|r|r|r|r|}
\hline Nacionalidad & 1996 & 2000 & 2003 & 2006 & 2009 & 2012 \\
\hline Marruecos & 1.370 & 2.179 & 4.481 & 7.582 & 12.678 & 17.832 \\
\hline Argelia & 108 & 339 & 1.480 & 2.315 & 3.995 & 5.965 \\
\hline Senegal & - & - & 586 & 1.085 & 2.192 & 3.349 \\
\hline Pakistán & - & - & 248 & 999 & 1.655 & 3.933 \\
\hline
\end{tabular}

Fuente: elaboración propia. 
Contar con una trayectoria mayor permite, en la mayoría de los casos, disponer de comunidades más estructuradas y capacitadas. Lo mismo ocurre con los espacios de culto: cuanto mayor recorrido tiene la comunidad, más posibilidades tiene de haber adquirido el local, bien a través del alquiler o bien, en la mayoría de los casos, en régimen de compra. No obstante, en los casos analizados, además de las dificultades propias de disponer de espacios suficientes y en buenas condiciones, se le añade una serie de obstáculos que propician la cada vez mayor dificultad para desplegar este tipo de centros, en algunas circunstancias y para algunas confesiones. Es como si el paso del tiempo, en vez de haber ayudado a normalizar la relación y canalizar las demandas, hubiera supuesto una marcha atrás o la puesta en guardia de la población autóctona. El rechazo de muchas y muchos vecinos a la apertura de centros de culto de confesiones minoritarias, en especial, de las mezquitas, ha sido manifiesto. Aquí experimentamos el afamado efecto Nimby, instalaciones sí, las que sean precisas, pero no cerca de mi domicilio. Es igualmente evidente que esta problemática social que surge en forma de negativa vecinal a la instalación de centros de culto musulmanes corre el peligro de hacer tambalear cualquier regulación en esta materia, e incluso, como efecto dominó, de perjudicar no solo la instalación de centros de esta confesión, sino de otras y de otro tipo de instalaciones.

Otro de los elementos influyentes en la fortaleza de estas comunidades es el de la financiación. Todas las comunidades analizadas se autofinancian a través de distintos medios, pero normalmente suelen ser las cuotas y aportaciones que hacen los mismos fieles, normalmente insuficientes y que no ayudan a la consolidación de la pluralidad religiosa existente. En estos montos recaudados, que sirven para mantener tanto los lugares de culto como los servicios de sacerdotes o imames o visitas de guías espirituales, interfieren dos elementos con cierta relevancia. Por un lado, la inexistencia de subvenciones institucionales dirigidas a estos fines y, por otro lado, la cada vez menor posibilidad de aportación económica de los miembros. En estos afectan las situaciones coyunturales de crisis, pero de forma estructural y sobre todo su economía precaria. Las únicas entradas económicas que algunas comunidades — evangélicas y musulmanas - reciben de las Administraciones se destina a proyectos educativos, culturales, de prestación de servicios y proyectos de cooperación. Es decir, sobre una economía endógena débil o sobre una ausencia todavía de políticas de subvención y promoción de la diversidad religiosa es muy difícil constituir una estructura fuerte que permita que se desarrolle la pluralidad religiosa realmente existente, luego su fortaleza es a grandes rasgos insuficiente. 
Teniendo en cuenta estos elementos, podemos concluir del análisis realizado anteriormente que en general, y con la excepción de las comunidades evangélicas con larga trayectoria, y de alguna la musulmana, la mayoría no goza de fortaleza, no está consolidada, lo que de entrada supone un estatus general de debilidad que impide la generación de capital social suficiente para hacerse valer en el actual espacio social vasco de las confesiones religiosas.

\subsection{Capital social de vínculoः una vinculación enriquecedora}

El capital de vinculación es el más desarrollado por las comunidades religiosas según la investigación que hemos desarrollado y que recibe el aval de la literatura internacional consultada sobre el tema. El estado del arte nos dice que a través de esta participación religiosa se desarrollan fuertes lazos sociales y que la religión como base de unión crea «relaciones más profundas, más amplias y más sostenibles» (Lockhart, 2005: 57). En el caso de las comunidades analizadas, podríamos decir que en todas ellas el capital de vinculación es el más presente, vivo y cultivado.

Las comunidades religiosas cumplen empíricamente un rol que va más allá de sus funciones principales: el desarrollo de las necesidades religiosas y espirituales de las personas. Se trata de grupos que, más allá de profesar una fe, suministran una diversidad de elementos a sus miembros practicantes, que abarcan las diferentes esferas de la vida personal, como veremos a continuación. Decimos empíricamente que la religión sobrepasa las dimensiones religiosa y espiritual, pero hemos de decir que, si atendemos a la etimología del término, la religión y las confesiones que particularmente analizamos, en un contexto de secularización, eso sí, cumplen a la perfección la función de religar personas, de crear comunidad, de crear un orden social a partir de unos elementos sagrados compartidos, en el núcleo de los cuales está la misma pervivencia de la comunidad. Aunque a alguien pueda extrañarle que en circunstancias tan adversas la religión cubra también las labores que en contextos más laicos hacen las redes inmigratorias, a continuación veremos que cumplen una gran función estabilizadora en el vínculo para personas que muchas veces están padeciendo situaciones de extrema incertidumbre en su proyecto migratorio.

\subsubsection{Aporte necesario de identidad}

Una cuestión que se ha repetido en el análisis de las distintas comunidades ha sido la gran importancia que las personas atribuyen a la fe profesada como parte indispensable de su identidad. En el caso de las comunidades ortodoxas y musulmanas, en particular, comprenden e interpretan la religión como parte indi- 
visible de su cultura. Presentan dificultades para distinguir religión y cultura, y viceversa. En consecuencia, la comunidad se convierte en un espacio necesario para el desarrollo de sus vidas, puesto que alejarse de ella supondría una pérdida o disfunción de su identidad. Vivir con identidades abiertas y flexibles no deja de ser un lujo que solo pueden permitirse personas que presentan un agregado de capitales muy elevado, no solo del social. No todos los inmigrantes o todas las personas creyentes son Maalouf (1999) o virtuosos del pluralismo, como dirían Peter Berger y Thomas Luckman (1995), o cosmopolitas desarraigados, en términos de Appiah (2003).

\subsubsection{Mantenimiento de la cultura de origen}

En cuanto que gran parte de las comunidades analizadas están compuestas por personas inmigradas, más en el caso de la fe ortodoxa y de la islámica, estas comunidades cumplen con la función de conservar la cultura del país de origen, en competencia más o menos abierta con la cultura de la sociedad receptora y con la cada vez más presente cultura global. En principio, los nuevos contextos son intrínsecamente, aunque no lo sean pretendidamente, asimilacionistas, aspecto que genera desazón en las personas que están al frente de las confesiones - sacerdotes ortodoxos, imames-, porque son demasiado fuertes y atractivos los estímulos que suministra la sociedad contra el mantenimiento de pautas culturales y religiosas de origen. Como dirían Berger y Luckmann, es difícil sostener una realidad subjetiva en crisis y sin retroalimentación de un marco cultural y religioso que facilite la vinculación y mutua fecundación entre realidad objetiva y subjetiva. En ausencia de esta relación dialéctica, los esfuerzos por mantener la cultura deben redoblarse. $Y$ donde se dice cultura, puede ponerse identidad o religión, o las tres juntas.

Como señalábamos en el apartado anterior, la fe y la cultura están tan estrechamente relacionadas para gran parte de los creyentes de estas confesiones, que este proceso de mantenimiento de la cultura a través de la religión debería desarrollarse de forma casi «natural». Como explica Francisco Javier de los Mozos (2013), cuanto mayor es la distancia cultural entre la propia y la de la sociedad de destino, más necesario se hace reproducir el universo simbólico que da sentido a las personas, aunque sea de manera temporal, ante un entorno que en un primer momento resulta hostil. En este sentido, la comunidad religiosa reproduce los símbolos, tradiciones e idiosincrasia de la cultura de origen, dotando de significado a las personas que forman parte de la misma, haciéndolas experimentar una continuidad inexistente pero que genere la sensación de no haber roto con la sociedad de origen. 
Las entidades religiosas son, por tanto, mecanismos de integración social. Contribuyen a la formación de estructuras de plausibilidad para el mantenimiento de una identidad originaria con una valoración o estima positiva; un lugar donde «los otros», los diferentes dentro de la sociedad española, pueden sentirse «normales»; claro está que estos centros no son el único mecanismo de reproducción de la identidad original, pero sí uno muy importante; y constituyen, sin duda ninguna, un medio poderoso de integración social. La integración de una persona socialmente minorizada pasa, al menos en parte, por su participación en mecanismos de integración colectiva, como estas entidades religiosas (PérezAgote, 2012: 41-42).

Esta necesidad se agudiza en las primeras generaciones. En nuestro análisis es un hecho patente en las comunidades ortodoxas, mientras que en las comunidades musulmanas se dan situaciones más diversas, sobre todo entre los más jóvenes, que tienden a constituir su identidad cultural en forma de aportación dual: nutrida tanto por la cultura de sus ascendientes como por la cultura de la sociedad vasca, de la que se sienten totalmente parte. Es verdad que en algunos casos el País Vasco es ya su lugar de nacimiento y/o socialización, pero, más que este dato, pesa la opción que hacen algunos de sus miembros. También pensamos que en el caso de la población potencialmente ortodoxa hay una desvinculación más grande entre la comunidad de referencia y la comunidad de creyentes que la que se da entre la población musulmana. Ahora bien, los creyentes, con los sacerdotes ortodoxos a la cabeza, sí observan que el cultivo de la fe debe ir acompañado inevitablemente del de la cultura y del de la participación en la comunidad.

Autores como Peter Ester (2006) constatan la importancia de estas nuevas generaciones en el desarrollo y mantenimiento del capital social. El autor analiza las comunidades reformistas germano-americanas en Estados Unidos y pone el énfasis en la próxima generación, afectada de lleno por la globalización, el pluralismo y el multiculturalismo, como motor en la no disminución del capital social de estas comunidades. El autor señala que las estrategias efectivas de socialización son una parte indispensable de la protección y crecimiento de un capital social efectivo y que, en este sentido, la siguiente generación siempre es el mejor test de sostenibilidad del capital social acumulado de los grupos inmigrantes.

Siendo que resulta tan importante el cultivo de esta cultura de origen o su transmisión a las nuevas generaciones, las comunidades desarrollan actividades vinculadas al aprendizaje del idioma, la historia y geografía del país de origen. No menos importante resulta el festejo de celebraciones significativas, tanto vinculadas a la religión como a la cultura, que, como explicábamos, no se diferencian de una forma clara. Como explican Pérez-Agote y Santiago (2009), estas comu- 
nidades religiosas resultan ser muy eficaces como lugar de celebración de estas fiestas, porque se dan encuentro y confraternidad entre las personas que las componen. En palabras de Portes: «Estas actividades no sólo mantienen y refuerzan la identidad del grupo, sino que además crean un espacio de contacto para sus miembros que es otras circunstancias no tendrían posibilidad de encontrarse» (Portes, 1995: 256-257).

\subsubsection{Servicios que se prestan}

Las tres confesiones religiosas y sus respectivos colectivos desempeñan una labor insustituible en la asistencia de servicios dirigidos tanto a los miembros de la comunidad como hacia la sociedad en su conjunto. Son varias las iniciativas encaminadas a esta asistencia, entre las cuales, casi todas las comunidades religiosas analizadas comparten la ayuda a las personas recién llegadas (tras un proceso migratorio) o la ayuda a aquellas personas que se encuentran en apuros para cubrir las necesidades básicas. Este tipo de ayuda se canaliza de maneras muy diversas, desde fondos destinados exclusivamente para ello, el alojamiento de personas en situación de exclusión en casas particulares, el reparto o banco de alimentos y ropa, etc. Las comunidades, a través de estas iniciativas, generan una solidaridad intragrupal que resulta de gran ayuda para muchas personas que o bien pasan a ser nuevos miembros de una sociedad que todavía les resulta hostil o que formando parte de la misma se encuentran en situaciones precarias y difíciles. Entonces, la comunidad se convierte en proveedora de múltiples recursos, desde la escucha hasta la búsqueda de trabajo, pasando por la resolución de conflictos o problemas que surgen, creando así una red de solidaridad entre las personas miembros.

La solidaridad y la ayuda mutua constituyen la base de la sobrevivencia, mitigan el traumatismo de la llegada a un nuevo contexto social y posibilitan la adaptación. La reconstrucción de antiguos lazos sociales en un nuevo contexto resulta así la condición misma para la reproducción del grupo doméstico y, de forma general, para la inserción social de los emigrantes (Comas y Pujadas, 1991: 38).

En no pocas ocasiones esta red intragrupal se convierte en redes de solidaridad, mayores entre distintas comunidades de la misma confesión que entre diferentes confesiones. En las comunidades evangélicas esta labor social se incrementa considerablemente porque disponen de multitud de programas y entidades que se dedican exclusivamente a estas labores orientadas a las personas con problemas de drogadicción, como es el caso de REMAR y RETO, visitas a centros de la tercera edad, visitas en prisiones a personas reclusas, así como proyectos de cooperación en otros países. 
Las diferentes comunidades realizan una gran labor dirigida a un colectivo que ha ido en alza en los últimos años. Nos referimos a las personas inmigrantes, que por lo general se encuentran en situación aún más vulnerable. Como señalan Pérez-Agote y Santiago (2009), las migraciones han impulsado un gran incremento de las funciones de la religión. Las comunidades religiosas juegan un papel fundamental en el apoyo y ayuda a estas personas, que influye significativamente en la integración de las mismas. En palabras de Pérez-Agote:

Las manifestaciones y expresiones religiosas constituyen estructuras de plausibilidad de una estima positiva dentro de una realidad social que minoriza socialmente al inmigrante. Cuanto menos funcionen los mecanismos de integración de la sociedad general (principalmente el sistema educativo, el mercado de trabajo y la adecuación de ambos) para la población inmigrante, mayor será la necesidad para esta población de obtener estima social y autoestima a partir de recursos propios. Cuanto peor funcionen aquellos mecanismos generales más importantes serán las funciones llevadas a cabo por la cultura y la religión originarias (Pérez-Agote, 2012: 41).

Por esta labor que las comunidades religiosas llevan a cabo nos atrevemos a decir que, en cierto sentido, y al igual que otras muchas entidades laicas, estas comunidades se han convertido en extensiones del Estado, cumpliendo en muchas ocasiones funciones que corresponden al Estado del bienestar. $Y$ es que, como señalan algunos autores: «Las organizaciones que no dependen del gobierno coayudan sustancialmente a la formación de capital social precisamente porque generan distintos tipos de interacciones, facilitando procesos de cooperación solidarios que generan confianza, además hacen accesibles los bienes y servicios públicos que el gobierno no logra brindar» (Putnam, 1993, en Espinoza y Flores, 2011: 5).

\subsubsection{Convivencia en diversidad}

Dentro de muchas de las comunidades religiosas, existe una realidad que enriquece tanto a la comunidad propia como a cada uno de los miembros de la misma. Nos referimos a la pluralidad de la que se componen estos grupos con base en la diversidad de orígenes de sus miembros. Mientras en algunas comunidades conviven personas de varios orígenes extranjeros, en otras hay una mayoría que es de origen vasco o español, y el resto, de origen extranjero. Esta realidad plural y diversa no supone un obstáculo para el desarrollo de las comunidades. Para salvar algunas dificultades que puedan surgir, como en el tema del idioma, las comunidades hacen esfuerzos para incorporar otras lenguas que sean o bien compartidas o bien conocidas por la mayoría o totalidad de las personas que participan de la liturgia. Siguiendo a Moreras: 
Existe un contexto global, en el que los colectivos inmigrados se relacionan comunitariamente con otros colectivos con los que se comparte una misma pertenencia religiosa, aunque no cultural o nacional, lo que facilita generar un sentido compartido de vinculación a un corpus doctrinal concreto. Ese sentimiento compartido puede generar una sensibilidad especial por los avatares y circunstancias que afectan a los miembros de este colectivo amplio, estén donde estén, con los que se comparte esta referencia, y se crean y movilizan solidaridades intercomunitarias que se expresan en contextos locales diferentes, $y$ de acuerdo con lógicas que pueden también ser diferentes, si bien se relacionan con las condiciones en que estos colectivos se hayan insertados socialmente, o bien con el clima político que se vive en tales contextos (Moreras, 2006bः28).

Tomando la religión como base de su unión, se crea un sentimiento de comunidad religiosa plural y colectiva.

No obstante, también existen algunos peligros que pueden desarrollarse a través de este capital de vínculo. Se trata de un peligro, o riesgo, cuando se trata de comunidades cerradas como mencionábamos al analizar las teorías de Coleman, cuando se refiere al principio de clausura. También podemos hablar, como Goffman (1984), de los grupos cerrados, o de hiperintegración, en términos de Olga Odgers-Ortiz:

Es precisamente la posibilidad que detentan algunas comunidades religiosas para crear comunidades bien delimitadas y para actuar en una multiplicidad de esferas de la vida cotidiana lo que puede conllevar la «hiper-integración» del individuo en una comunidad hermética. Nuevamente: la hiper-integración facilitará la resolución de problemas inmediatos, pero frenará la posible interacción del individuo con la sociedad amplia, obstaculizando el proceso de subjetivación y manteniéndolo aislado al interior de la comunidad (Odgers, 2005: 5).

Según esta autora, el éxito y el peligro de las comunidades religiosas se basa además en su carácter totalizador y absoluto, en el sentido de que poseen/logran un monopolio que pocas o ninguna institución más consigue sobre el manejo de un cúmulo de creencias que orientan tanto ética como moralmente las normas por las que se rigen los miembros de estas comunidades. A lo largo del análisis, hemos observado en palabras de muchos de los miembros de estas comunidades la veracidad de este hecho, con lo que la manera en que empleen ese poder, al igual que las formas de liderazgo que desarrollen, resultará crucial para la participación más allá del propio grupo. No obstante, esta realidad se retroalimenta en muchas ocasiones por la dificultad o imposibilidad de muchas personas para participar en la sociedad a otros niveles, entre los cuales se encuentra el ámbito político, con lo que la adhesión a la comunidad se intensifica, siendo el único espacio donde 
estas personas se sienten valoradas, más allá o pese a sus diferencias. Otra de las razones por las que las comunidades adquieren esta modalidad de clausura se debe al sentimiento de amenaza o rechazo que puedan experimentar por parte de la sociedad, donde el repliegue hacia el interior supone una defensa para la comunidad. Por lo tanto, resulta clave que se generen dinámicas de conocimiento, entendimiento y respeto entre la sociedad en su conjunto y las comunidades religiosas. Más aun que desde el entramado político se gestione este hecho de la mejor manera para que estas prácticas sean nulas o al menos ínfimas.

\subsection{Capital social puente: insuficiencia de lazos débiles}

Las comunidades religiosas se crean para dar respuesta a las necesidades espirituales y de fe de las personas. Y a través de estas, en el caso de las comunidades surgidas a través de procesos migratorios, para recrear el universo simbólico al que pertenecen.

Una vez creadas, estas comunidades tienden a institucionalizarse, aunque los tiempos y ritmos son dispares para cada una de ellas. Esta institucionalización se refiere a la inscripción de las comunidades en alguno de los diferentes registros existentes. La mayoría opta por inscribirse como entidad religiosa, mientras un grupo más reducido lo hace como asociación cívica. Existe disparidad en el tiempo transcurrido desde su creación, hasta la inscripción e, incluso, en el tipo de registro por el que optan. Respecto al primer punto, se deduce que es necesario un tiempo de andadura para finalmente poder realizar estos trámites, que en no pocas ocasiones son dirigidos por instancias o federaciones superiores. En cuanto al tipo de inscripción, sobre todo entre comunidades ortodoxas y musulmanas, la vía pasa por constituirse como asociación cultural en muchos de los casos, para posteriormente inscribirse en el Registro de Entidades Religiosas.

\subsubsection{Federaciones y entidades aglutinadoras}

Este es el primer punto que nos permite obtener información sobre el capital puente de las comunidades. La pertenencia a federaciones o instancias aglutinadoras ofrece en la mayoría de los casos unas posibilidades y herramientas que por ellas mismas no son capaces de desarrollar. De la misma manera, les dota de fuerza y legitimidad ante otras instancias y Administraciones públicas. Entre las comunidades analizadas, se observan diferencias ante este hecho. Mientras que las comunidades ortodoxas tienen relaciones directamente con las Iglesias madre a nivel nacional y/o en el país de origen, con una estructura más parecida a la Iglesia católica en cuanto al modelo jerárquico se refiere, siendo una Iglesia centralizada, las comunidades evangélicas y musulmanas, en cambio, no responden 
a esta modalidad. Dentro de las diferentes Iglesias evangélicas también existen modelos de organización diferenciados, desde los más jerárquicos a los más congregacionales, siendo estas últimas la mayoría de las presentes en el País Vasco. Quizá por esta diversidad, tanto en esta confesión como en la musulmana, existe mayor dispersión, y en un intento de unificación, se crean diferentes consejos y federaciones tanto a nivel local como nacional.

Entre las tres confesiones analizadas, podemos afirmar que la Iglesia evangélica es la que mayores lazos mantiene en este sentido. Exceptuando tres de las comunidades más recientes, las denominadas Iglesias neopentecostales o neocarismáticas, que suelen necesitar de una experiencia previa de funcionamiento para después pasar a formar parte de entidades superiores, el resto pertenece o bien al Consejo Evangélico del País Vasco y/o a federaciones nacionales correspondientes, la FADE y FEREDE. Para las comunidades locales, formar parte de estas plataformas supone la posibilidad tanto de recibir apoyo para distintas necesidades, de trámites burocráticos, legal, como de, a través de estas, ser actores interlocutores con las Administraciones públicas y el ámbito político. Una tarea necesaria pero que en solitario a duras penas podrían realizar por sí mismas. Esta pertenencia les posibilita al mismo tiempo el contacto con el resto de comunidades y las dota de una pertenencia más amplia.

El caso de las comunidades musulmanas resulta dispar. Aunque también existen este tipo de consejos y federaciones tanto a nivel local como nacional y forman parte de estas instancias, estas están mucho más diseminadas. En las entrevistas analizadas, en más de una ocasión, se alude a la necesidad de mayor cohesión de las comunidades y de entidades que cumplen esta función, aunque la respuesta a su propia petición se resuelve creando más entidades de este tipo y no llegando a cumplirse la necesidad expresada, sino que más bien se crea mayor dispersión, si cabe.

\subsubsection{Relaciones con confesiones religiosas}

Aludíamos al comienzo a la organización de carácter jerárquico de las comunidades ortodoxas. Por ello, quizá por la proximidad y los lazos históricos que esta Iglesia mantiene con la Iglesia católica, y como fruto de la relación entre sus élites de gobierno, hemos observado la ayuda y el apoyo que esta última les presta. Siendo comunidades un tanto precarias en cuanto a algunos aspectos de su fortaleza, la relación que mantienen con la Iglesia católica les posibilita en muchos casos el disponer de lugares de culto a modo de cesión. Esta relación, aunque no exclusiva, puesto que el resto de comunidades han mantenido relaciones con algunas personas o entidades de carácter católico, sí resulta especial en el caso de las comunidades ortodoxas. 
Además de estas relaciones con la confesión mayoritaria, las relaciones con el resto de confesiones o el diálogo interreligioso no es una práctica que se desarrolla en las confesiones analizadas. Todas ellas se muestran respetuosas con la diversidad religiosa y la valoran positivamente, pero las relaciones que se generan de manera habitual responden a relaciones más personalizadas entre algunos de los miembros de las distintas confesiones. Pareciera que este tipo de relaciones pudiera dotar a las comunidades y confesiones en general de un mayor empoderamiento o fuerza de unión frente a las dificultades con las que se encuentran en la sociedad. Unas dificultades marcadas por una sociedad en la que la diversidad religiosa no se ha contemplado demasiado al menos hasta el momento y que tampoco resulta de mucho agrado en términos generales. Esto mismo lo podríamos trasladar a las Administraciones y partidos políticos, pero este punto lo desarrollaremos en el último apartado. No obstante, no se deben menospreciar las iniciativas en el camino del diálogo interreligioso que existen en el País Vasco y de las que algunas de las comunidades analizadas han participado, aunque este diálogo no haya alcanzado cotas mayores de intercambio que el conocimiento y respeto mutuo, algo que no se puede subestimar.

En otro nivel de relaciones, las que se crean con otras entidades, asociaciones y ONG, no hemos detectado un gran abanico de relaciones. Sí que existe relación con entidades como Cáritas o la Fundación Ellacuria (ambas de naturaleza católica), de las que muchas comunidades de las tres confesiones señalan haber obtenido beneficios, bien por la cesión de espacios para llevar a cabo actividades relacionadas con el culto o de formación, bien por el apoyo e interlocución en iniciativas de carácter político.

\subsubsection{Presencia en los medios de comunicación}

Por último, para el capital puente, resulta de interés la presencia de las comunidades en los medios de comunicación, por la influencia que ejercen en la generación de pensamiento y opinión pública. En general, podemos concluir que los medios de comunicación, al tratar el tema de la diversidad, o bien pecan de una falta de información y formación acuciante, o bien esconden un interés por deslegitimizar a estas confesiones, por su dependencia, especialmente del mercado y de los poderes públicos. Existe la preocupación generalizada de que, teniendo en cuenta la influencia que estos medios ejercen en los imaginarios de las personas, la mayoría de las veces el peso de las noticias recae en informar sobre acontecimientos negativos relacionados o con la membresía (por origen) o con la misma confesión (sobre todo en el caso del islam y el panorama internacional relacionado con el terrorismo). Las pocas veces que señalan sentirse conformes con la imagen que se 
presenta de ellas es cuando informan sobre festividades importantes, donde los miembros de las comunidades son protagonistas de la noticia, pero, en opinión de estas personas, estas noticias se presentan en los medios de comunicación de manera anecdótica y creen que se tiñen de cierto carácter exótico. Esta realidad no resulta en absoluto beneficiosa para las comunidades, puesto que, además de no contar con un estatus de normalidad ante la sociedad, la influencia de estas informaciones no hace más que mermar su imagen, y es que «los medios de comunicación pretenden ser fuentes de información fiable. Esta suposición opera en el usuario de noticias incluso si, en la práctica, el texto asume un punto de vista parcial o sesgado dentro del debate social. La ausencia de puntos de vista alternativos al alcance del lector refuerza este efecto» (García y Uriarte, 2011: 74).

Para contrarrestar estas informaciones dañinas, muchas comunidades, sobre todo las evangélicas y las musulmanas, cuentan con sus propios medios de difusión: redes sociales, página web, incluso algún programa televisivo y radiofónico. Sin embargo, el universo al que llegan a través de estos canales propios no se asemeja al que los medios de comunicación logran, por lo que para informarse a través de estos primeros la persona tiene que tener un interés particular para acceder a ellos, aunque, por otro lado, es de pensar que es al público al que interesan llegar, dejando para procesos posteriores acceder a otras esferas más amplias.

Las relaciones fuera de cada comunidad no son demasiado extensas, aunque hay diferencias en función de que lo sean dentro o fuera de las confesiones: más intensas entre los de la confesión y menos entre confesiones. En la medida en que las comunidades religiosas tienen capacidad de transformarse en comunidades integradas en las dinámicas sociales locales, hacen de soporte en el arraigo y en la integración social de las personas que conforman el grupo, lo que contribuye de manera positiva a la cohesión social y a las relaciones sociales existentes en el territorio. No obstante, en no pocos casos, estas comunidades están más inmersas en la defensa de los intereses e identidades del propio grupo, de manera que descuidan la tares de tender puentes con otros grupos y personas del entorno. Es probable que los grupos y comunidades no hayan logrado un proceso de maduración e institucionalización suficiente, lo que les obliga, primero, a consolidar el grupo, para solo después entablar relaciones con el resto, y por extensión con la sociedad.

El hecho de no entablar relaciones externas viene precedido del temor a la disolución de la unidad e identidad grupales, y es ahí donde la comunidad religiosa se convierte tanto en soporte de cohesión entre los miembros del grupo como en muro de contención hacia el exterior. A pesar de que la realidad de las comunidades es muy diversa, la autopreservación interna se experimenta en comunidades 
y colectivos de las tres confesiones, pero sobre todo en la ortodoxa e islámica, que son las más constituidas por personas de origen extranjero y con temor a que su identidad se diluya, porque la sienten en peligro como consecuencia de que se autoperciben en su cualidad de minoría.

Granovetter (1973) fue el primer autor que hizo referencia a los tipos de relaciones que se generan tanto dentro de las comunidades o los grupos, a los que denomina «lazos fuertes», que en principio parecían ser los que mayores conexiones podían generar. No obstante, según el autor, serán los «lazos débiles», los que se generan a través de las relaciones con otros grupos, comunidades o individuos, los generadores de capital social puente, porque permiten disponer de informaciones diferentes y valiosas. Otra de las consecuencias importantes de la generación de este tipo de lazos y del capital social puente es la importancia que suponen para la cohesión social, por lo que sería de desear que entre las comunidades religiosas se fomentaran los lazos débiles, porque por pura acumulación de este tipo de lazos débiles se genera confianza. Aunque en un primer momento se desee generar lazos fuertes, porque a simple vista parecen ser más decisivos, también los débiles cumplen una función decisiva, aunque partan de un tipo de relaciones que no necesariamente implican compromisos sólidos entre grupos, pero sí relaciones.

\subsection{Capital social de acceso: fragilidad como agentes e interlocutores políticos}

Un tercer y último tipo de capital social se refiere a las relaciones existentes entre las comunidades religiosas y las instancias y estructuras de poder, como los partidos políticos o las Administraciones en general. La creación y mantenimiento de este tipo de capital resulta de gran ayuda, porque la participación de las comunidades en espacios de decisión tanto local como provincial o de comunidad autónoma supone poder trasladar las preocupaciones y necesidades en estos ámbitos de decisión, así como poder exponer y ofrecer de forma directa las diferentes ofertas y actividades que estas comunidades llevan a cabo. Estamos hablando de un ejercicio de ciudadanía que situaría a estas comunidades en una posición activa en la construcción tanto de la cohesión social como de la propia sociedad. El capital de acceso por definición y por necesidad debería radicar en los grupos, pero en ausencia debería ser la misma Administración la que dispusiera de medios y procedimientos para fortalecer este capital con los grupos. En un esquema lógico-teórico, estos grupos empoderados deben de tener capacidad para intervenir e influir y hacerse valer en su relación con otros grupos y con la Administración, pero, de cara a gobernar en lógica de gobernanza esta pluralidad religiosa, la Administración puede hacer mucho de su parte. 


\subsubsection{Débil desarrollo del ámbito religioso y arbitrariedad en su gestión pública}

Las relaciones que las comunidades religiosas han mantenido con las Administraciones públicas y los partidos políticos son en general escasas, y en algunos casos, residuales. De las mantenidas, son dispares las valoraciones: desde encuentros positivos y fructíferos hasta otros que se califican como nulos, e incluso un tanto humillantes. Lo cierto es que existe una gran arbitrariedad en los contactos y respuestas que las instituciones ofrecen a las comunidades, siendo dos los elementos que hemos podido rescatar. Por un lado, la realidad de la diversidad religiosa no ha sido, al menos, hasta el momento, un hecho que se haya contemplado como relevante desde las instancias tanto administrativas como políticas vascas, siendo muestra de ello la falta de protocolos de actuación y de normativas de desarrollo al respecto. Por otro lado, otro tema que crea controversia es la tendencia a argumentar este vacío con base en la naturaleza laica del Estado. En este sentido, «apelar a la "laicidad de las instituciones públicas" suele ser una estrategia para argumentar la existencia de un marco legal que impide a las administraciones públicas intervenir respecto a lo religioso» (Moreras, 2006a: 33). Es una forma de liberalismo cultural o religioso, que normalmente es inocuo para atender y afrontar la realidad. El marco constitucional español habla del principio de aconfesionalidad, por el cual la libertad religiosa debería respetarse a la vez que el Estado se declara incompetente en materia religiosa. Ahora bien, sea teóricamente la laicidad, sea textualmente la aconfesionalidad, el resultado es que no se da pie a que los grupos religiosos tengan una presencia acorde a su densidad social, a la vez que por inacción se termina siempre fortaleciendo la religión «nacional».

A nivel estatal sí que existe la Ley Orgánica de Libertad Religiosa del año 1980 y los acuerdos de cooperación y estatus de arraigo que concede el Estado a algunas confesiones. No obstante, desde las comunidades se critica la falta de cumplimiento de estas directrices por parte de las instituciones y el trato favorable que la Iglesia católica recibe al respecto. Es más, lo grave muchas veces es el desconocimiento de la legalidad existente por parte de las autoridades públicas.

Ante esta noción de la laicidad, desde diversos sectores de la sociedad se ha propuesto el término laicidad incluyente. Esta perspectiva renovada acepta el papel positivo que pueden ejercer las diferentes confesiones religiosas. Aun estando a favor de la total separación entre el ámbito político y el religioso, fomenta la participación de estas confesiones en el espacio público, entendiendo que pueden aportar en este espacio a la cohesión y vertebración de la sociedad, de manera que ayudan a consolidar el capital social (López Camps, 2007).

Sin embargo, desde un punto de vista legal, el Estado se define como aconfesional, es decir, que ninguna religión tendrá carácter estatal o que este no se 
identifica con ninguna religión en particular. Esto se recoge en la Constitución española de 1979, en su artículo 1616, al mismo tiempo que define la libertad de creencias como un derecho fundamental. Incluso estando recogido de esta manera en la Constitución, se precisa de un tiempo para crear una consciencia de esta diversidad de confesiones y en que se explicite el pluralismo religioso existente. Este pluralismo religioso, en la praxis, se encontraba con obstáculos en el ámbito de las libertades, con lo que la necesidad de garantía de igualdad de condiciones para la práctica religiosa se materializó a instancias de los poderes públicos en la Ley Orgánica de Libertad Religiosa de 1980. A pesar de este avance, en la reglamentación jurídica, tanto en la Constitución como en la ley, se seguía distinguiendo en términos de binomio entre «la Iglesia» (haciendo referencia a la Iglesia católica) y «las otras minorías». Además, a pesar de que esta ley orgánica marcara un cambio en la relación Estado-Iglesia, al mismo tiempo, en 1976 y 1979, se firmaban los acuerdos internacionales de cooperación entre el Estado español y la Santa Sede, reconociéndole a la Iglesia católica privilegios que ninguna otra confesión disfrutaría. De modo que la necesaria igualdad no se vio cristalizada, ya que se mantuvo un estatus diferenciado entre la religión predominante y las otras religiones minoritarias.

Frente a esta situación que perpetuaba la diferencia, se dio un paso adelante en el reconocimiento de algunas minorías religiosas, confiriendo a estas confesiones el estatus de «notorio arraigo», teniendo en cuenta como criterio el arraigo visible de estas confesiones en el país, así como su tradición histórica y número de fieles. Hasta el momento, son las siguientes las confesiones que han obtenido este reconocimiento.

Tabla 3. Confesiones religiosas con notorio arraigo según fecha de concesión

\begin{tabular}{|l|c|}
\hline \multicolumn{2}{|c|}{ NOTORIO ARRAIGO } \\
\hline CONFESIÓN & FECHA \\
\hline Islam & 1989 \\
\hline Judaísmo & 1989 \\
\hline Protestantismo & 1989 \\
\hline Iglesia de Jesucristo de los Últimos Días & 2003 \\
\hline Testigos Cristianos de Jehová & 2006 \\
\hline Federación Entidades Budistas de España & 2007 \\
\hline Iglesia ortodoxa & 2010 \\
\hline
\end{tabular}

Fuente: elaboración propia. 
De la mano de este reconocimiento, en el año 1992 se negocia y se firma una serie de acuerdos para hacer efectivo el mandato constitucional de cooperación del Estado con las confesiones religiosas. A continuación, mostramos la relación de acuerdos de cooperación firmados hasta el momento.

Tabla 4. Confesiones religiosas que han firmado acuerdos de cooperación con el Estado según fecha

\begin{tabular}{|l|r|}
\hline \multicolumn{2}{|c|}{ ACUERDOS DE COOPERACIÓN } \\
\hline \multicolumn{2}{|c|}{ CONFESIÓN } \\
\hline Iglesia católica & $\begin{array}{r}15 \text { de septiembre de } 1976 \\
3 \text { de enero de } 1979\end{array}$ \\
\hline Federación de Entidades Evangélicas de España & 10 de noviembre de 1992 \\
\hline Federación de Comunidades Judías de España & 10 de noviembre de 1992 \\
\hline Comisión islámica de España & 10 de noviembre de 1992 \\
\hline
\end{tabular}

Fuente: elaboración propia.

A pesar de las medidas tomadas, resulta obvio que no han sido suficientes $y$, en este sentido, el mismo director general de Relaciones con las Confesiones Religiosas (en funciones hasta febrero de 2012), en una entrevista, mencionaba la necesidad de reformar la Ley Orgánica de Libertad Religiosa de 1980, a la que anteriormente hacíamos alusión, para que en ella se recoja el fin de las restricciones a la apertura de lugares de culto, entendiendo la importancia que estos espacios suponen para las comunidades religiosas.

Como veíamos anteriormente, la posibilidad de acceso a sus propios centros es uno de los mayores problemas con los que se encuentran las personas creyentes y las mismas religiones minoritarias, bien sea por las dificultades asociadas a las excesivas exigencias que lleva aparejadas, o bien por las protestas o negación por parte de la población a su establecimiento. Otro de los aspectos que se vería modificado por la propuesta de reforma es el de potenciar la participación y el protagonismo de las comunidades autónomas y los ayuntamientos en materia de diversidad religiosa. En este sentido, aunque las competencias están diferenciadas, es crucial la importancia de las Administraciones autonómicas, y sobre todo de la local, por su proximidad a los ciudadanos y por tratarse del espacio donde se visibiliza y confluye esta realidad, a la vez de tratarse del lugar donde se discuten y renegocian las dimensiones actuales de la noción de ciudadanía (HolstonAppadurai, 1999). Un último aspecto a renovar y remover es el de las relaciones entre lo político y lo religioso. Más exactamente relacionado con los acuerdos de 
los que anteriormente hablábamos, el cambio se aplicaría en relación con «las otras confesiones», a las que, como mencionábamos, se les reconoce el «notorio arraigo», concepto que por el momento resulta un tanto impreciso.

Estas propuestas nacen del Gobierno español dirigido por el Partido Socialista, que ha impulsado una serie de iniciativas entre las cuales cabe destacar la Fundación Pluralismo y Convivencia, nacida en el año 2001, por acuerdo del Consejo de Ministros y a propuesta del Ministerio de Justicia. Es un organismo del sector público estatal que trata de contribuir a la puesta en marcha de programas y proyectos de carácter cultural, educativo y de integración social de las confesiones religiosas minoritarias que tengan firmados acuerdos de cooperación con el Estado o que hayan sido reconocidas como de notorio arraigo en España. En este sentido, una de las líneas que se fomentan desde la fundación es la de la investigación sobre el pluralismo religioso. Dentro de esta línea de investigación hasta el momento se han realizado dos tipos de estudios. Por un lado, un «mapa» de la realidad de las minorías religiosas por comunidades autónomas, donde se enmarca la publicación que citábamos de Pluralidades Latentes; Minorías religiosas en el País Vasco, que hasta el momento se ha realizado en diez comunidades autónomas. Por otro lado, se ha trabajado en un estudio de carácter cualitativo en siete comunidades autónomas (incluida la CAPV), en la línea de la gestión pública de la diversidad religiosa, del que se han extraído diferentes manuales por ámbitos de actuación, con el objetivo de que sirvan como herramientas de actuación para las Administraciones locales.

Una de las razones de aportar esta descripción es la de situar el tema en el ámbito geográfico que nos ocupa, el País Vasco, para conocer cuál ha sido la realidad de gestión de esta diversidad en el mismo. Para ello, debemos hacer alusión a ese trabajo de investigación que se llevó a cabo en el año 2009 de manera simultánea en siete comunidades autónomas. En cada una de ellas se realizó una serie de entrevistas que abarcaban los tres ámbitos públicos institucionales de la CAPV: municipales, forales y el Gobierno Vasco. Al mismo tiempo, se trabajaba con una comunidad religiosa en cada uno de los cuatro municipios en los que se realizó el estudio, en nuestro caso: Vitoria/Gasteiz, Bilbao, Yurreta e Irún.

Tras realizar estas entrevistas, la percepción general ha sido la de que se trata de un tema que, en términos generales, no se había contemplado desde la necesidad de ser gestionado desde estas instancias. En casi la mayoría de los casos, directamente se relaciona con el ámbito de la inmigración y, en muchas ocasiones, cualquier demanda de carácter religioso es derivada a la dirección, departamento o persona técnico de inmigración en caso de contar con este perfil. Cuando se hace referencia a las minorías religiosas, no cabe la idea de contemplar el ejercicio 
del derecho a la libertad religiosa como un derecho ciudadano universalizado $y$, por tanto, de todas y todos los ciudadanos, sino que se relaciona casi exclusivamente con las personas extranjeras. No obstante, en no pocas ocasiones, el problema se sustenta en la falta de conocimiento y de normalización a través de protocolos adecuados de gestión, más que actitudes contrarias, que cabe decir, también hemos encontrado por el camino, aludiendo a la idea de relegar los asuntos religiosos a la esfera privada de las personas, sin que las Administraciones públicas tengan que hacerse cargo de los mismos. Estamos aquí ante el debate de las diferentes maneras que pueden existir para desarrollar la laicidad.

Durante la legislatura del PSE en el Gobierno Vasco, comprendida hasta el año 2012, se han dado algunos pasos adelante, además de los ya mencionados: se ha elaborado un Anteproyecto de Ley sobre apertura de centros de culto. Lo cierto es que esta ley por el momento ha quedado en mera propuesta y, de haberse llevado a cabo, hubiese sido de gran ayuda para gestionar de manera igualitaria todas las demandas realizadas en esta línea en los últimos tres años.

Muchas de las cuestiones relacionadas con el desarrollo de la actividad religiosa entran en lo que se denomina como gestión local, es decir, en manos de los ayuntamientos correspondientes, puesto que es en el ámbito local, en el municipio, donde se desarrolla la vida y, en este sentido, el marco legal que recoge estos asuntos apenas hace referencia a este ámbito. Esta falta de claridad en sus competencias y deberes deriva en una arbitrariedad en la actuación de estos ayuntamientos, un hecho denunciado por las comunidades religiosas, como observábamos en el apartado de los obstáculos a los que se enfrentan. En consecuencia, en el territorio vasco, hemos presenciado realidades muy dispares ante una misma demanda. Por poner un ejemplo claro, ante la demanda de apertura de una mezquita, por parte de la misma comunidad, la respuesta institucional y sus consecuencias han sido bien distintas en municipios como Bilbao y Portugalete, municipios que se sitúan a escasos $15 \mathrm{~km}$ de distancia. Una de las diferencias objetivas entre los dos ayuntamientos es la del partido que gobierna, que normalmente es una de las variables influyentes en la toma de decisiones ante aspectos relacionados al menos con el ámbito religioso, algo, una vez más, que deriva en desigualdades. A pesar de las diferencias, lo cierto es que, desde este ámbito, por causa de la inexperiencia en el tema y, en consecuencia, por falta de experiencias exitosas o buenas prácticas donde inspirarse, por un lado, y por el impacto político que las polémicas derivadas crean, las acciones políticas locales optan por mantener una triple dimensión de prudencia, discreción y posibilismo (Moreras, 2006b:33). 


\subsubsection{Interés y comunicación desigual ante el entramado político}

Como señalábamos al comienzo, las relaciones que las comunidades mantienen con las Administraciones públicas o con los partidos políticos son desiguales. Para iniciar este tipo de interacciones, entendemos que el empoderamiento y la capacitación de los colectivos y comunidades juegan un papel crucial. Esta podría ser una de las razones, por su corta trayectoria, por la que las comunidades ortodoxas son las que menos contactos han mantenido. Esto no quiere decir que no se hayan dado encuentros, sobre todo con las Administraciones más próximas, con los ayuntamientos.

En el caso de muchas de las comunidades evangélicas y musulmanas, y sobre todo a través de las entidades aglutinadoras o coordinadoras que hemos mencionado - consejos y federaciones-, sí que han mantenido contactos con los tres niveles de las Administraciones públicas: ayuntamientos, diputaciones forales y Gobierno Vasco. Para cumplir con este cometido resultan de gran importancia tanto la capacidad de interlocución como los agentes que se destinan a esta labor. Mientras que, a través del Consejo Evangélico del País Vasco, se canalizan las demandas, necesidades y aportes que las comunidades realizan a estas instituciones; en el ámbito del islam, esta interlocución no resulta tan clara para estas instancias. Superar esta incapacidad es una demanda tanto de las Administraciones públicas hacia estas comunidades como una carencia de la que las mismas comunidades musulmanas son conscientes. En ausencia de capacitación hay un liderazgo débil y una interlocución insuficiente.

En la creación de relaciones que generan este tipo de capital social de acceso existe un componente que resulta decisivo: la confianza. En no pocas ocasiones en las entrevistas mantenidas con las comunidades se ha aludido tanto a la arbitrariedad y variabilidad en la gestión administrativa y política ante cuestiones y demandas de algunas comunidades religiosas como a una pronunciada discriminación hacia estas confesiones minoritarias. La calidad de las relaciones y de la negociación depende de las personas que están implicadas y de su voluntad. Este contexto ha creado una desconfianza hacia estas instancias. Por último, no todas las comunidades expresan la necesidad ni el interés por mantener este tipo de relaciones. Probablemente, las comunidades evangélicas, dadas su orientación religiosa y su dispersión, son las que menos lo precisan como confesión, aunque algunas de sus comunidades ansían establecer y mantener este acceso. 


\section{Conclusiones}

En el presente artículo hemos tratado de ofrecer una panorámica del capital social del que disponen o carecen tres de las confesiones minoritarias presentes en el País Vasco: la ortodoxa, la evangélica y la musulmana.

Comenzando por la fortaleza de estas comunidades, elemento que cimienta las bases, hemos podido comprobar que esta no es demasiado consistente en la mayoría de las comunidades analizadas. El tiempo de implantación o la veteranía de estas comunidades resultan cruciales en el desarrollo y capacitación de las mismas. Respecto a cada una de las confesiones, podría decirse que a grandes rasgos la confesión ortodoxa tiene una fortaleza débil, que la musulmana tendría una fortaleza media, más derivada de su número que de su estructura, y que la evangélica, a pesar de su dispersión interna en comunidades y credos, tendría una fortaleza más consistente tanto por el número como por la existencia de creyentes autóctonos previos a la emergencia de las migraciones. En este último caso, observaremos cómo el capital cultural y el económico permiten disponer de un crédito que luego les permite exportarlo al capital social.

En segundo lugar, podemos afirmar que casi la totalidad de comunidades religiosas analizadas cuida el capital social de vinculación, bien a través del aporte identitario, de la variedad de servicios y actividades que ofrecen y cubren, o bien por el apoyo que muestran tanto a los países de origen como a países que, sin ser los originarios de la inmigración, se encuentran en situación de necesidad.

No obstante, tanto el capital social de puente y el de acceso son los menos desarrollados en las tres confesiones, aunque con ciertas diferencias significativas, como veíamos en el apartado de los resultados, siendo la confesión evangélica la que dispone de mayor desarrollo de estos dos capitales. En otros casos, la preponderancia del capital social de vinculación, en ocasiones forzada, lleva a un desarrollo muy limitado de los capitales sociales de puente y acceso.

A pesar de ello, cabe pensar que en las próximas décadas se normalizarán y, en parte, se naturalizarán relaciones e interacciones que hoy nos parecen imposibles y que con el transcurso del tiempo irán adquiriendo una cotidianeidad aproblemática. De manera que estos dos capitales sociales puedan reforzarse si junto al esfuerzo de las comunidades y sus fieles las instituciones y poderes públicos caminan en el mismo sentido y facilitan estas relaciones y avances. 


\section{Bibliografía}

Álvarez de los Mozos, Francisco Javier (2013). Capital social de las Asociaciones de Inmigrantes. Asociaciones bolivianas, colombianas, ecuatorianas y peruanas en Bilbao, Madrid y Valencia. Universidad de Deusto.

Appiah, Kwane Anthony (2003). «Los fundamentos de los derechos humanos». En Michael Ignatieff. Los derechos bumanos como politica e idolatría (pp. 115128).

Berger, Peter y Luckmann, Thomas (1995). Modernidad, pluralismo y crisis de sentido. Paidós.

Bilbao, Saioa; Ruiz, Andrea y Urrutia, Gorka (2011). «Las confesiones minoritarias en el País Vasco: caracterización, necesidades y espacios religiosos». En E. Ruiz Vieytez (dir.) La diversidad religiosa en el País Vasco. Bilbao: Universidad de Deusto.

Bilbao, Saioa; Uriarte, Luzio y Urrutia, Gorka (2014). «Religiones minoritarias y contexto local: relaciones con la administración pública y el vecindario». En Dolores Morondoro y Eduardo J. Ruiz Vieytez (eds.). Diversidad religiosa, integración social y acomodos. Un análisis desde la realidad local en el caso vasco (pp. 53-82). Bruselas: Peter Lang.

Bilbao, Saioa; Uriarte, Luzio y Urrutia, Gorka (2014). «Acomodos y "desacomodos" desde la perspectiva de las minorías». En Dolores Morondoro y Eduardo J. Ruiz Vieytez (eds.). Diversidad religiosa, integración social y acomodos. Un análisis desde la realidad local en el caso vasco (pp. 53-82). Bruselas: Peter Lang.

Bourdieu, Pierre (1986): «The Forms of Capital». En John Richardson. Handbook of Theory and Research for the Sociology of Education (pp. 241-258). New York: Greenwood Press.

Comas, Dolores y Pujadas, Juan José (1991). «Familias migrantes: reproducción de la identidad y del sentimiento de pertenencia». Revista Papers, 36: 33-56.

Ester, Peter (2006). «Bonding, bridging, and believing Social capital of DutchAmerican Reformed communities». Fifth Triennial Conference of the International Society for the Study of Reformed Communities (ISSRC), "Reformed Communities in an Era of Growing Globalization and Pluralism", Princeton, New Jersey, 9-12 de julio de 2006. Disponible en: <https://www.calvin.edu/ henry/ISSRC/Conferences/Papers/ester06.pdf $>$.

Gallo, María Teresa y Garrido, Rubén (2009). El capital social. ¿Qué es y por qué importa? Madrid: IUAES- Universidad de Alcalá. 
García, Diego y Uriarte, Luzio (2011). «Las minorías religiosas y los medios de comunicación». En E. Ruiz Vieytez (dir.). La diversidad religiosa en el País Vasco. Bilbao: Universidad de Deusto.

Geertz, Clifford (1997). La interpretación de las Culturas. Barcelona: Gedisa.

Goffman, Erving (1984). Frame Analysis. An Essay of The Organization of Experience. New York: Harper and Row.

Granovetter, Mark (1973). «The Strength of Weak Ties»+ American Journal of Sociology, 78(6): 1360-1380.

IKuSPEgi (2007). Base de datos de la encuesta realizada a población inmigrante extranjera en el País Vasco.

López, Jordi (2007). »La necesaria laicidad». CIDOB d’Afers internacionals, 77: 175-196.

MaAlouf, Amin (1999). Identidades asesinas. Madrid, Alianza Editorial.

Moreras, Jordi (2006b). «Creencias más allá de las fronteras: las expresiones religiosas en contexto migratorio». Puntos de Vista: Cuadernos del Observatorio de las Migraciones y la Convivencia Intercultural de la Ciudad de Madrid, 7: 21-47.

Odgers-Ortiz, Olga (2005). «Migración, identidad y religión* aproximaciones al estudio del papel de la práctica religiosa en la redefinición identitaria de los migrantes mexicanos». Amérique Latine Historie et Mémoire, Les Cabiers ALHIM, 7.

Pérez-Agote, Alfonso (2012). Cambio religioso en España: Los avatares de la secularización. Madrid: Centro de Investigaciones Sociológicas.

Pérez-Agote, Alfonso y Santiago, José Antonio (2009). La nueva pluralidad religiosa, Madrid: Ministerio de Justicia.

Portes, Alejandro (1995). «Economic Sociology and the sociology of Inmigration. An Overview». En A. Portes (ed.). The Economic Sociology of Inmigration. New York, Russel Sage Fundation.

Putnam, Robert (1993a). Making Democracy Work: Civic Traditions in Modern Italy. Princeton: Princeton University.

Putnam, Robert (1993b). «The Prosperous Community: Social Capital and Public Life». The American Prospect, 4(13): 35-42.

Ruíz Vieytez, Eduardo J. (2010). Pluralidades Latentes. Minorías religiosas en el País Vasco. Barcelona: Icaria.

Ruíz Vieytez, Eduardo J. (2011). La diversidad religiosa en el País Vasco. Nuevos retos sociales y culturales para las políticas públicas. Bilbao: Universidad de Deusto. 
Woolcock, Michael (1998). «Social Capital and Economic Development: Toward a Theoretical Synthesis and Policy Framework». Theory and Society, 27(2): 151-208.

Woolcock, Michael (2001). «The place of social capital in Understanding Social and Economic Outcomes». ISUMA Canadian Journal of Policy Research, 2(10): 11-17.

Woolcock, Michael y Sweetser, Anne (2002). «Bright Ideas: Social CapitalThe Bonds That Connect». ADB Review, 34 (2). 